Perspective

\title{
The Dark Side of Light: A Transdisciplinary Research Agenda for Light Pollution Policy
}

\author{
$\underline{\text { Franz Hölker }}^{1}$, Timothy Moss $^{2}$, Barbara Griefahn ${ }^{3}$, Werner Kloas ${ }^{1}$, Christian C. Voigt ${ }^{4}$, \\ Dietrich Henckel ${ }^{5}$, Andreas Hänel ${ }^{6}$, Peter M. Kappeler ${ }^{7}$, Stephan Völker ${ }^{8}$, Axel Schwope ${ }^{9}$, \\ Steffen Franke ${ }^{10}$, Dirk Uhrlandt ${ }^{10}$, Jürgen Fischer ${ }^{11}$, Reinhard Klenke ${ }^{12}$, Christian Wolter ${ }^{1}$, and \\ Klement Tockner ${ }^{1,13}$
}

\begin{abstract}
Although the invention and widespread use of artificial light is clearly one of the most important human technological advances, the transformation of nightscapes is increasingly recognized as having adverse effects. Night lighting may have serious physiological consequences for humans, ecological and evolutionary implications for animal and plant populations, and may reshape entire ecosystems. However, knowledge on the adverse effects of light pollution is vague. In response to climate change and energy shortages, many countries, regions, and communities are developing new lighting programs and concepts with a strong focus on energy efficiency and greenhouse gas emissions. Given the dramatic increase in artificial light at night ( 0 - 20\% per year, depending on geographic region), we see an urgent need for light pollution policies that go beyond energy efficiency to include human well-being, the structure and functioning of ecosystems, and inter-related socioeconomic consequences. Such a policy shift will require a sound transdisciplinary understanding of the significance of the night, and its loss, for humans and the natural systems upon which we depend. Knowledge is also urgently needed on suitable lighting technologies and concepts which are ecologically, socially, and economically sustainable. Unless managing darkness becomes an integral part of future conservation and lighting policies, modern society may run into a global self-experiment with unpredictable outcomes.
\end{abstract}

Key Words: artificial light; energy efficiency; lighting concept; light pollution; nightscape; policy; sustainability; transdisciplinary

\section{INTRODUCTION}

In 2009, the UN's Year of Astronomy drew worldwide attention to an area affected by a long neglected environmental stressor: the increasing illumination of our nightscapes. The Year of Astronomy coincided with the 400th anniversary of Galileo's first observations with a telescope in Padua. However, to look at today's firmament Galileo would have to escape to remote areas for his research. This is because the Earth has become brighter at night. The rapid proliferation of electric lights has drastically reordered nightscapes across the globe, in terms of both light intensity and light spectrum (Cinzano et al. 2001, Elvidge et al. 2007). Although artificial lighting has clearly enhanced the quality of human life (Jakle 2001, Doll et al. 2006), the benefits are accompanied by hidden costs. Astronomers were the first to recognize that sky glow hampers the detection of faint celestial objects, obliging them to conduct their observations from darker areas or from orbit (Riegel 1973, Smith 2009). It is only very recently that the multiple negative effects of artificial lighting on ecology, human health, and social well-being have gained broader recognition (Jakle 2001, Rich and Longcore 2006, Navara and Nelson 2007).

\footnotetext{
${ }^{1}$ Leibniz Institute of Freshwater Ecology and Inland Fisheries, Berlin, ${ }^{2}$ Leibniz Institute for Regional Development and Structural Planning, Erkner, ${ }^{3}$ Leibniz Research Centre for Working Environment and Human Factors, Dortmund, ${ }^{4}$ Leibniz Institute for Zoo and Wildlife Research, Berlin, ${ }^{5}$ Technische Universität Berlin, Department of Urban and Regional Planning, ${ }^{6}$ Dark Sky Germany, Museum am Schölerberg, Osnabrück, ${ }^{7}$ Leibniz Institute for Primate Research, Göttingen, ${ }^{8}$ Technische Universität Berlin, Department of Energy and Automation Technology, Berlin, ${ }^{9}$ Astrophysikalisches Institut Potsdam, ${ }^{10}$ Leibniz Institute for Plasma Science and Technology, Greifswald, ${ }^{11}$ Freie Universität Berlin, Institute for Space Sciences, ${ }^{12}$ Helmholtz Centre for Environmental Research, UFZ, Leipzig, ${ }^{13}$ Freie Universität Berlin, Institute for Biology
} 
Light pollution is now a widely accepted term for adverse effects of artificial light on nature and humans (Longcore and Rich 2004, Navara and Nelson 2007). Nearly all living organisms, including human beings, have evolved under a natural rhythm of day and night. Interestingly, around $30 \%$ of all vertebrates and more than $60 \%$ of all invertebrates world-wide are nocturnal (Hölker et al. 2010). As lighting becomes brighter and extends farther into rural areas and offshore in marine systems (see Appendix 1), the distinction between day and night becomes blurred. Our understanding of the adverse effects of light pollution is vague and based mostly on purely observational case studies. Nonetheless, there is clear evidence that artificial lighting can alter physiology, including hormonal balance, as well as behavior, orientation, organism fitness, food web interactions, and biotope connectivity (Rich and Longcore 2006, Navara and Nelson 2007). The artificial disturbance of the natural day/night cycle may, as a result, have serious psycho-physiological and even medical consequences for humans, along with ecological and evolutionary implications for animals, plants, and even entire terrestrial, freshwater, and marine ecosystems (Rich and Longcore 2006, Navara and Nelson 2007). Light pollution is most probably an important but underestimated driver behind the erosion of provisioning, e.g., loss of light-sensitive species and genotypes; regulating, e.g., decline of nocturnal pollinators such as moths and bats; and cultural ecosystem services, e.g., loss of aesthetic values such as the visibility of the Milky Way (Rich and Longcore 2006, Carpenter et al. 2009, Smith 2009). The principal effects become most apparent at the interfaces between the physiological, ecological, and socioeconomic realms (Fig. 1). The problem is escalating worldwide as artificial lighting is rapidly increasing by around 6\% per year (range: $0-20 \%$; Table 1).

\section{THE CURRENT FOCUS ON ENERGY EFFICIENCY}

Artificial lighting consumes $19 \%$ of total global electricity, accounting for greenhouse gas emissions of $1900 \mathrm{Mt}$ of $\mathrm{CO}_{2}$ per year (OECD/IEA 2006). It is no surprise that current artificial lighting policies focus primarily on energy efficiency and greenhouse gas emissions (e.g., OECD/IEA 2010), although safety, astronomical, and other considerations appear sporadically (see Appendix 2). The International Energy Agency has calculated that the systematic use of 'least life-cycle cost' lighting solutions (see Appendix 3) from 2008 onward would reduce the electricity consumption attributable to lighting until 2020 by 1311 TWh and $763 \mathrm{Mt}$ of $\mathrm{CO}_{2}$ emissions per year compared to projections on the basis of current policies (OECD/ IEA 2006).

Recently, the European Ecodesign Directive established a framework to phase out the incandescent lamp and other particularly energyintensive lighting products, e.g., high-pressure mercury lamps (The European Parliament and the Council of the European Union 2009). This step could reduce $\mathrm{CO}_{2}$ emissions in the EU by approximately $42 \mathrm{Mt}$ per year, corresponding roughly to a $10 \%$ reduction of the greenhouse gas emissions the EU promised to achieve under Kyoto (Denneman 2009, Managenergy 2010). In the United States, President Obama has proposed a scheme for more energy-efficient lamps and lighting equipment as part of his climate change policy. This would result in savings of approximately $20 \mathrm{Mt} \mathrm{CO}_{2}$ annually (The White House 2009). Similar activities are reported inter alia for China, Australia, and New Zealand (OECD/ IEA 2006, 2010).

Within such policy frameworks, many countries, regions, and communities are developing new lighting programs and concepts. For example, the EU has launched a number of programs, e.g., GreenLight www.eu-greenlight.org, E-Street www .e-streetlight.com, to adopt efficient lighting systems and to initiate a permanent market transition. Although most of these programs and concepts are driven by energy efficiency motives alone, there remain causes for concern. For example, technological innovations that help improve the efficiency of energy appliances and systems often lead to greater energy use because of direct 'rebound' effects (Herring and Roy 2007, Charles 2009). New technologies and reduced costs could generate steep increases in the overall use of lighting and may stimulate innovative additional uses for lighting (Herring and Roy 2007, Fouquet and Pearson 2006). Lighting efficiency has doubled over the past 50 years in the UK; however, per capita electricity consumption for lighting increased fourfold over the same period (Fouquet and Pearson 2006). Due to the development and use of new lighting technologies, e.g., compact fluorescent 
Table 1. Pristine sites with natural sky background brightness can be identified by measuring the sky background (astronomical unit mag/arcsec ${ }^{2}$ in the visual range corresponds to a negative logarithmic scale of sky luminance) at modern astronomical observatories. Older observatories were built at dark sites close to cities. Today, these peri-urban sites are characterized by bright skies. Some observatories in the southwest of the USA were able to preserve relatively dark skies because of lighting ordinances (low pressure sodium lamps, full cut-off luminaires) in the nearby cities, resulting in a decrease of sky brightness in Flagstaff, Arizona since 1982 (Lockwood et al. 1990). The increase of the sky background depends on different model assumptions for several observatories (Garstang 1989). Indirect values can be derived from the increase of power consumption and lamp efficiency for street lighting.

\begin{tabular}{|c|c|c|c|c|c|}
\hline & Period & $\begin{array}{l}\text { Sky brightness (mag/ } \\
\left.\operatorname{arcsec}^{2}\right)\end{array}$ & $\begin{array}{c}\text { Annual } \\
\text { increase } \\
(\%)\end{array}$ & Cause & References \\
\hline \multicolumn{6}{|l|}{ Pristine } \\
\hline Mt. Graham, AZ, USA & $2000-2008$ & $21.5-21.8$ & 0 & solar activity & Pedani 2009 \\
\hline Hawaii, USA & $1986-1996$ & $21.3-21.9$ & 0 & solar activity & Krisciunas 1997 \\
\hline Cerro Tololo/Chile & $1992-2006$ & $22.0-21.2$ & 0 & solar activity & Krisciunas et al. 2007 \\
\hline $\begin{array}{l}\text { Kitt Peak/Mt. Hopkins, } \\
\text { AZ, USA }\end{array}$ & $1988-1999$ & $\Delta 0.1-0.2$ & $1-2$ & ordinances & Massey and Foltz 2000 \\
\hline \multicolumn{6}{|l|}{ Urban } \\
\hline Flagstaff, AZ & $1974-1982$ & $\Delta 0.4$ & 5 & & Lockwood et al. 1990 \\
\hline IAO, India & $2003-2007$ & $21.3-21.1$ & 5 & & Stalin et al. 2008 \\
\hline \multirow[t]{2}{*}{ Mt. Wilson, USA } & $1973-1999$ & $19.8-18.8$ & 3.6 & $\begin{array}{l}\text { city lights } \\
\text { Los Angeles }\end{array}$ & Teare 2000 \\
\hline & $1900-2000$ & $\Delta 2.7$ & 2.5 & $\begin{array}{l}\text { city lights } \\
\text { Los Angeles }\end{array}$ & Garstang 2004 \\
\hline Mt. Hamilton, CA, USA & $1950-1975$ & $21.9-20.6$ & 5 & city lights & Walker 1973 \\
\hline Ekar, Asiago, Italy & $1960-1995$ & $21.6-20.2$ & 10 & city lights & Cinzano 2000 \\
\hline G. Haro, Mexico & $1994-1997$ & $20.5-20.0$ & 19 & city lights & Carrasco et al. 1998 \\
\hline NAO, Japan & 1958/1978/1989 & $20.5 / 19.5 / 17.6$ & $5-17$ & $\begin{array}{l}\text { city lights } \\
\text { Tokyo }\end{array}$ & Isobe and Kosai 1998 \\
\hline
\end{tabular}

\section{Worldwide}

Expert guess 


\begin{tabular}{|c|c|c|c|c|c|}
\hline $\begin{array}{l}\text { UK Campaign to Protect } \\
\text { Rural England (CPRE) }\end{array}$ & $1993-2000$ & & 4 & DMSP data & CPRE 2003 \\
\hline UK McNeill & $1984-1999$ & $1.86 x \operatorname{lmh}$ & 4.2 & street light & McNeill 1999 \\
\hline UK Fouquet/Pearson & $1950-2000$ & $5 x \operatorname{lmh}$ & 3.3 & $\begin{array}{l}\text { overall } \\
\text { energy } \\
\text { consumption } \\
\text { for light }\end{array}$ & $\begin{array}{c}\text { Fouquet and Pearson } \\
2006\end{array}$ \\
\hline USA & $1967-1970$ & & 20 & $\begin{array}{l}\text { energy }+ \\
\text { efficiency }\end{array}$ & Riegel 1973 \\
\hline France & $1990-2000$ & & 3 & energy & ADEME 2007 \\
\hline Germany & $1950-1990$ & & 8 & $\begin{array}{l}\text { energy + } \\
\text { efficiency }\end{array}$ & Hänel 2001 \\
\hline
\end{tabular}

Note: IAO India = Indian Astronomical Observatory, NAO Japan = National Astronomical Observatory of Japan

lamp (CFL), light-emitting diode (LED), organic light-emitting diode (OLED), we can expect a dramatic drop in the cost of lighting services, a desirable end in itself, but with possibly higher energy consumption and wider loss of dark nightscapes as a consequence. Technological innovations should, therefore, not only save consumers money, but also consider human health, ecological, and socioeconomic aspects.

\section{BEYOND ENERGY EFFICIENCY}

Whereas air, noise, or water pollution have been high priority policy issues for decades, light pollution remains scientifically, culturally, and institutionally in the dark. Given the dramatic increase in artificial light in recent years, we see an urgent need for research on the physiological, human health, ecological, and socioeconomic significance of the loss of the night that addresses how illumination can be improved both technically and institutionally yet having fewer adverse effects. Managing darkness has to be an integral part of future conservation planning and illumination concepts. If not, our modern society may run into a global self-experiment with unpredictable outcomes (Fig. 1).
Any attempts to reduce light pollution run up against positive connotations of lighting which are deeply ingrained in modern societies. Culturally, light is a symbol of enlightenment, modernity, urbanity, and security (Jakle 2001). Policy initiatives against light pollution therefore need to take into consideration the many advantages of artificial lighting, real and perceived, for economic production, social lifestyles, and security while at the same time addressing its negative side effects. For this, a sound understanding of the historical, socioeconomic, and cultural reasons for the emergence and dissemination of lighting systems is needed. We then need to ask how far recent changes in attitudes, in particular relating to the environment and human health, are creating openings for a shift in policy and practice. Part of this process involves identifying and building up a coalition of interest around the light pollution issue, incorporating such diverse stakeholder groups as ecologists, astronomers, and health professionals, but also electricity utilities, lamp manufacturers, property owners, local businesses, city planners, or those concerned about nighttime security.

Thus, the research needed is transdisciplinary, i.e. it should cut across boundaries between scientific disciplines and between science, policy, and 
Fig. 1. Hypothetical impacts of exposure to artificial light at night. The main impacts, both with respect to light intensity and color spectra, emerge at the interfaces between the different physiological, ecological, and socioeconomic aspects.

\section{A self-experiment with unpredictable outcomes}

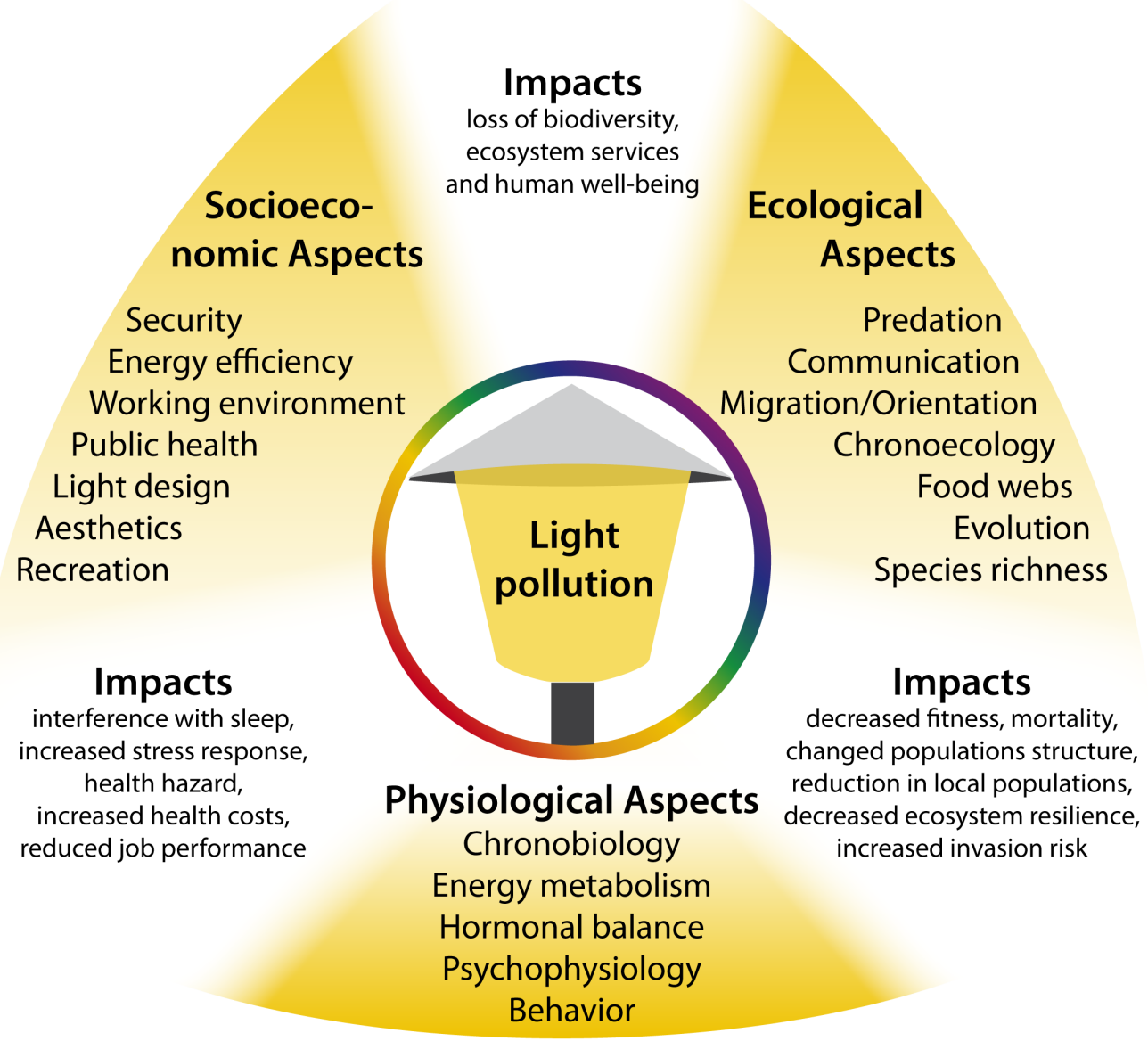

practice and should address facts, practices, and values (Wiesmann et al. 2008). The following natural, social, and engineering science questions are central to this research agenda:

- What characteristics of light disrupt human health and ecological communities?
- How does light pollution interact with other stressors such as air, water, and noise pollution, or climate change?

- What technologies can address the environmental, health, and economic disadvantages of current lighting practices in different areas or settlement types? 
- What alternative lighting strategies and policies are politically, culturally, and economically viable?

- To what extent are users willing to minimize light pollution and adopt alternatives?

Such research should validate indicators and guidelines, set priorities for human health and environmental protection, identify technical and economic possibilities for improvements in lighting, and develop sustainable lighting concepts and techniques for future nightscapes.

With our present understanding, there is little choice but to develop guidelines in accordance with energy efficiency criteria and the few available case studies on the ecological and health impacts of lighting. The Commission Internationale de l'Éclairage (CIE), the International Dark-Sky Association (IDA; ww w.darksky.org), and the Illuminating Engineering Society of North America (IESNA 2000) provide preliminary recommendations, illustrating how local lighting ordinances and innovative designs may promote low impact, energy-efficient and aesthetically pleasing lighting systems (e.g., CIE 1997, 2000, 2003). Promising options are, for example, lamps that direct their light more accurately toward where it is needed, lamps that emit light with a spectral distribution causing minimal harm, timers and sensors to turn lights on only when needed, and the consideration for lightsensitive areas, especially the periphery of residential areas, forests, parks, and shores of water bodies. The comprehensive and transdisciplinary research advocated here will result in more advanced regulations and guidelines at, in particular, the national level and the development of intelligent, i.e., adaptive and context-dependent, lighting concepts for local communities. These will help countries, regions, and cities to maximize the social and economic benefits of artificial light at night, while minimizing its negative and unintended ecological and health impacts. On this basis, future generations will be able to experience nightscapes comparable to those which Galileo knew without having to travel to the Australian Outback or the Chilean Andes.
Responses to this article can be read online at: http://www.ecologyandsociety.org/vol15/iss4/art13/ responses/

\section{Acknowledgments:}

We are grateful to Steve Carpenter, Jens Krause, Elisabeth K. Perkin, and Michael Monaghan for helpful comments. This work was supported by Milieu (FU Berlin), the Leibniz Association, the Senatsverwaltung für Bildung, Wissenschaft und Forschung, Berlin, and the Federal Ministry of Education and Research, Germany.

\section{LITERATURE CITED}

Agence de l'Environnement et de la Maîtrise de I'Energie (ADEME). 2007. Energie et Patrimoine Communal, Enquête 2005. [online] URL: http://ww w2.ademe.fr/servlet/getDoc?cid=96\&m=3\&id=489 56\&ref $=19684 \& p 1=$ B.

Campaign to Protect Rural England (CPRE). 2003. Night blight! Campaign to Protect Rural England, London, UK.

Carpenter, S. R., R. DeFries, T. Dietz, H. A. Mooney, S. Polasky, W. V. Reid, R. J. Scholes. 2009. Science for managing ecosystem services: beyond the Millennium Ecosystem Assessment. Proceedings of the National Academy of Sciences USA 106:1305-1312.

Carrasco, B. E., A. Carramiñana, F. J. SanchezSesma, and F. J. Lermo. 1998. Protection of the observatorio astrofisico "Guillermo Haro". Astronomical Society of the Pacific Conference Series 139:141-149.

Charles, D. 2009. Leaping the efficiency gap. Science 325:804-811.

Commission Internationale de l'Éclairage (CIE). 1997. Guidelines for minimizing sky glow. CIE Technical Report 126-1997, Vienna, Austria.

Commission Internationale de l'Éclairage (CIE). 2000. Guide to the lighting of urban areas. CIE Technical Report 136-2000, Vienna, Austria. 
Commission Internationale de l'Éclairage (CIE). 2003. Guide on the limitation of the effects of obtrusive light from outdoor lighting installations. CIE Technical Report 150-2003, Vienna, Austria.

Cinzano, P. 2000. The growth of light pollution in North-Eastern Italy from 1960 to 1995. Memorie della Società Astronomica Italiana 71:159-165.

Cinzano, P., F. Falchi, and C. D. Elvidge. 2001. The first world atlas of the artificial night sky brightness. Monthly Notices of the Royal Astronomical Society 328:689-707.

Denneman, J. 2009. Light relief. Parliament Magazine 281:42.

Doll, C. N. H., J.-P. Muller, and J. G. Morley. 2006. Mapping regional economic activity from night-time light satellite imagery. Ecological Economics 57:75-92.

Elvidge, C. D., P. Cinzano, D. R. Pettie, J. Arvesen, P. Sutton, R. Nemani, T. Longcore, C. Rich, J. Safran, J. R. Weeks, and S. Ebener. 2007. The nightsat mission concept. International Journal of Remote Sensing 28:2645-2670.

Fouquet, R., and P. Pearson. 2006. Seven centuries of energy services: the price and use of light in the United Kingdom (1300-2000). The Energy Journal 27:139-177.

Garstang, R. H. 1989. The status and prospects for ground-based observatory sites. Annual Review of Astronomy and Astrophysics 27:19-40.

Garstang, R. H. 2004. Mount Wilson observatory: the sad story of light pollution. The Observatory 124:14-21.

Hänel, A. 2001. The situation of light pollution in Germany. Preserving the Astronimical Sky IAU Symposium 196:142-146.

Herring, H., and R. Roy. 2007. Technological innovation, energy efficient design and the rebound effect. Technovation 27:194-203.

Hölker, F., C. Wolter, E. K. Perkin, and K. Tockner. 2010. Light pollution as a biodiversity threat. Trends in Ecology and Evolution 25:681-682.
Illuminating Engineering Society of North America (IESNA) 2000. Technical memorandum on light trespass: research, results and recommendations. TM-11-00, IESNA, New York, New York, USA.

Isobe, S., and H. Kosai.1998. Star watching observations to measure night sky brightness. Astronomical Society of the Pacific Conference Series 139:175-184

Jakle, J. A. 2001. City lights. Illuminating the American night. John Hopkins University Press, Baltimore, Maryland, USA.

Krisciunas, K. 1997. Optical night-sky brightness at Mauna Kea over the course of a complete sunspot cycle. Publications of the Astronomical Society of the Pacific 109:1181-1188.

Krisciunas, K., D. R. Semler, J. Richards, H. E. Schwarz, N. B. Suntze, S. Vera, and P. Sanhueza. 2007. Optical sky brightness at Cerro Tololo InterAmerican Observatory from 1992 to 2006. Publications of the Astronomical Society of the Pacific 119:687-696.

Lockwood, G. W., D. T. Thompson, and R. D. Floyd. 1990. Sky glow and outdoor lighting trends since 1976 at the Lowell Observatory. Publications of the Astronomical Society of the Pacific 102:481-491.

Longcore, T., and C. Rich. 2004. Ecological light pollution. Frontiers in Ecology and the Environment 2:191-198.

Managenergy. 2010. Key information related to energy efficiency. European Commission on Energy. [online] URL: http://www.managenergy.net/ ee.html.

Massey, P. and C. B. Foltz. 2000. The spectrum of the night sky over Mount Hopkins and Kitt Peak: changes after a decade. Publications of the Astronomical Society of the Pacific 112:566-573.

McNeill, G. 1999. Street lighting: a development and economic history since 1924. Lighting Journal 64:37.

Narisada, K., and D. Schreuder. 2004. Light pollution handbook. Springer, Dordrecht, The Netherlands. 
Navara, K. J., and R. J. Nelson. 2007. The dark side of light at night: physiological, epidemiological, and ecological consequences. Journal of Pineal Research 43:215-224.

Organisation for Economic Co-operation and Development (OECD)/International Energy Agency (IEA). 2006. Light's labour's lost - policies for energy-efficient lighting. OECD/IEA, Paris, France.

Organisation for Economic Co-operation and Development (OECD)/International Energy Agency (IEA). 2010. Energy efficiency policies and measures database. [online] URL: http://www.iea. org $/$ textbase $/ \mathrm{pm} /$ ?mode $=\mathrm{pm}$.

Pedani, M. 2009. Sky surface brightness at Mount Graham: UBVRI science observations with the large binocular telescope. Publications of the Astronomical Society of the Pacific 121:778-786.

Rich, C., and T. Longcore, editors. 2006. Ecological consequences of artificial night lighting. Island Press, Washington, D.C., USA.

Riegel, K. W. 1973. Light pollution. Science 179:1285-1291.

Smith, M. 2009. Time to turn off the lights. Nature 457:27.

Stalin C. S., M. Hegde, D. K. Sahu, P. S. Parihar, G. C. Anupama, B. C. Bhatt, and T. P. Prabhu. 2008. Night sky at the Indian astronomical observatory during 2000-2008. Bulletin of the Astronomical Society of India 36:111-127.

Teare, S. W. 2000. Night sky brightness at Mt. Wilson observatory. The Observatory 120:313-317.

The European Parliament and the Council of the European Union. 2009. Directive 2009/125/EC of the European Parliament and of the Council of 21 October 2009 establishing a framework for the setting of ecodesign requirements for energyrelated products. Official Journal of the European Union L 285: 10-35.

The White House, Office of the Press Secretary. 2009. Obama Administration launches new energy efficiency efforts. Press Release, The White House, Washington, D.C., USA. [online] URL: http://www .whitehouse.gov/the press office/Obama-Administration-

\section{Launches-New-Energy-Efficiency-Efforts/}

Walker, M. F. 1973. Light pollution in California and Arizona. Publications of the Astronomical Society of the Pacific 85:508-519.

Wiesmann, U., G. Hirsch Hadorn, H. HoffmannRiem, S.Biber-Klemm, W. Grossenbacher, D. Joye, C. Pohl, and E. Zemp. 2008. Enhancing transdisciplinary research: a synthesis in fifteen propositions. Pages 433-441 in G. Hirsch Hadorn, H. Hoffmann-Riem, S. Biber-Klemm, W. Grossenbacher-Mansuy, D. Joye, C. Pohl, U. Wiesmann, and E. Zemp, editors. Handbook of transdisciplinary research. Springer. Dordrecht, The Netherlands. 


\section{Appendix 1. Sources of light at night}

Light pollution is a by-product of industrial civilization, which alters the natural patterns of light and dark in ecosystems and includes direct glare, and chronically increased illumination; all of which can disrupt terrestrial, freshwater, and marine ecosystems to varying degrees (Longcore and Rich 2004).

- Light pollution by urban development includes street lights, illuminated buildings, bridges and towers, commercial advertising, factories, parking places, airports, flaring of natural gas, sky beamer, illuminated sporting venues, and also car headlights. It is most distinct in industrialized, densely populated areas of Europe, North America, and Japan and in metropolises in the Middle East and North Africa (e.g. Cinzano et al. 2001, Longcore and Rich 2004, Elvidge et al. 2007).

- The main sources of artificial light in marine environments include vessels, lighthouses, fisheries using light to attract fish (e.g. squid fisheries), as well as gas flares at oil and gas platforms (offshore gas flaring) (e.g. Cinzano et al. 2001, Elvidge et al. 2007, Elvidge et al. 2009).

\section{LITERATURE CITED}

Cinzano, P., F. Falchi, and C. D. Elvidge. 2001. The first world atlas of the artificial night sky brightness. Monthly Notices of the Royal Astronomical Society 328: 689-707.

Elvidge, C. D., P. Cinzano, D. R. Pettie, J. Arvesen, P. Sutton, R. Nemani, T. Longcore, C. Rich, J. Safran, J. R. Weeks, and S. Ebener. 2007. The Nightsat mission concept. International Journal of Remote Sensing 28: 2645-2670.

Elvidge C. D., D. Ziskin, K. E. Baugh, B. T. Tuttle, T. Ghosh, D. W. Pack, E. H. Erwin, and M. Zhizhin. 2009. A fifteen year record of global natural gas flaring derived from satellite data. Energies 2: 595-622.

Longcore, T., and C. Rich. 2004. Ecological light pollution. Frontiers in Ecology and the Environment 2:191-198. 


\section{Appendix 2. Lighting guidelines and policies}

Security is an important aspect in urban lighting guidelines. Various CIE (Commission Internationale de l'Éclairage) technical reports exist on this topic (e.g. CIE 1995, 2000). However, besides security aspects, pioneering regional laws have been introduced to protect dark sky close to astronomical observatories. Methods to reduce sky glow were defined by the IAU (International Astronomical Union) and the CIE (Cayral et al. 1980). On the Canary Islands and in Chile, international observatories are protected by law (Instituto de Astrofísica de Canarias (IAC) 1988, Ministerio de Economia, Fomento y Reconstruccion 1998). The regional law of Lombardy, Italy, and the national law of Slovenia are influenced by both energy efficiency and astronomical concerns (LR Lombardia 17/2000, Uradni List 2007). The Fatal Light Awareness Program (FLAP) is an example of efforts by cities (Toronto, in this case) to address the issue of light pollution that links both energy efficiency and ecology; in this case bird conservation (FLAP 2010). The Catalonian Law strives to restore and protect natural nighttime conditions for the benefit of fauna, flora, and the general ecosystem (Font 2002).

\section{LITERATURE CITED}

Cayrel, R., F. G. Smith, A. J. Fisher, and J. B. de Boer. 1980. Guidelines for minimizing urban sky glow near astronomical observatories. IAU/CIE, Paris.

Commission Internationale de l'Éclairage (CIE). 1995. Recommendations for the lighting of roads for motor and pedestrian traffic. CIE Technical Report 115-1995, Vienna, Austria.

Commission Internationale de l'Éclairage (CIE). 2000. Guide to the lighting of urban areas. CIE Technical Report 136-2000, Vienna, Austria.

FLAP. 2010. Fatal Light Awareness Program. [online] URL: http://www.flap.org/flap_home.htm.

Font, M. R. 2002. La ley catalana de ordenación ambiental del alumbrado para la protección del medio nocturno. Autonomies 28, Barcelona.

Instituto de Astrofísica de Canarias (IAC). 1988. Ley Cielo 31/1988, Bol, Ofic, Est. 246. [online] URL: http://www.iac.es/eno.php?op1=4\&op2=10\&lang=en

LR Lombardia 17/2000 (updated with D.G.R. Lombardia 2611/2000, L.R. Lombardia 38/2004 and the Regulations D.G.R. Lombardia 7/6162/2001). [online] URL: http://cielobuio.org/index.php?option=com_content\&view=article\&id=471.

Ministerio de Economia, Fomento y Reconstruccion. 1998. Decreto Suprema No. 686, Chile. [online] URL: http://www.opcc.cl/.

Uradni List. 2007. Republike Slovenije, St. 81. [online] URL: http://www.uradni-list.si/1?year=2007\&ofs $=40$. 


\section{Appendix 3. Life-cycle cost of a lighting system}

The life-cycle cost of a lighting system is the sum of its initial cost (the sum of the purchase price and the installation cost) and the discounted operating costs (the energy and maintenance costs discounted over time to take account of the time-dependent value of money). In this analysis a real discount rate of 5\% is assumed (OECD/IEA 2006).

\section{LITERATURE CITED}

Organisation for Economic Co-operation and Development (OECD)/International Energy Agency (IEA). 2006. Light's labour's lost - policies for energy-efficient lighting. OECD/IEA, Paris, France. 